\title{
Comics in Translation
}

\section{Rodrigo Faveri e Dennys Silva-Reis (Eds.)*}

Academic interest in the study of comics originates with the attention given to certain forms of popular narrative and mass communication, especially film and other visual media. This is not just another recent academic phenomenon, a certain tradition in the study of comics has been evolving in Brazil for about 40 years. The first work we have on the specific issue of the comic book translation is Oficina de Tradução do Francês: Traduzindo Quadrinhos by Maria Lúcia Jacob D. Barros (2009). Despite, it is still a new thing, so to speak. Those comics cultures in which the practice of translation is closely linked to the practice of original production -sometimes even overcoming that in numbers, as in Brazil - the kind of investigation the authors proposein the present volume touches some of the fundamental questions about authorship and identity in the study of comics translation.

The symposium Quadrinhos em Tradução, held at the XI Congresso Internacional da ABRAPT, in September 2013 at Universidade Federal de Santa Catarina, was the first known event so far dedicated only to comics translation which brought together researchers from different academic areas and professional segments (translators, teachers, researchers in master's and doctoral level) ${ }^{1}$. Through the eleven presentations during one whole day, the audience filled the room. Not all the guests could be present to the event, but the seeds of a new initiative were dispersed by the members of the group

\footnotetext{
* The editors of the volume would like to thank Professor Mauri Furlan (UFSC) for his invaluable help as well as editorial advice during the first attempt to put this collection together.

1 The original symposium was coordinated by Rodrigo Faveri with the collaboration and participation of Professor Paulo Ramos (Unifesp).
} 
FAVERI, R.; SILVA-REIS, D. - Comics in Translation

that were able to be there, and we managed to establish something in common, an idea if not complete, at least in part, with some of the elements that characterize the comic translation practice and reception in Brazil.

But what are we talking about, when we talk about comics, anyway? There are many definitions available around and also a strong emphasis on the idea that you cannot define them. Among those available, however, it can be said that comics are a type of multimodal text in which the narrative property is assigned by the sequentiality that can be inferred from the juxtaposition of multimodal resources (of imagetic and linguistic nature) which produce essential effects like narrative temporality and spatiality.

Comics are not a lesser form of literature, a minor literature. Even if comics are understood as a hybrid cultural product belonging to a certain stage of development of culture in history, they represent an autonomous way of narrative expression characterizing society and the culture they are produced.

At the end of the event in 2013, we were aware of that kind of exclusive condition displayed by comics arising from its peculiar combination of imagetic systems of meaning, linguistic and other specific graphics capabilities that comics possess. They are characterized by a kind of narrative text that shares common elements with other types of imagetic narrative like cinema, illustrated stories, animations, among others. We could also mention the Brazilian foto novela, a media phenomenon that has lasted in Brazil for a long time, a kind of adult comics to follow the same standards of comics.

During the symposium, we realized the need to explore the variety of phenomena associated with the practice and theory of comics translation. An editorial event of undeniable impact on the publishing market and in contemporary literacy practices, comics occupy a peculiar place in the investigation of the phenomena related to translation practices. Given its nature and for being recognized as a culturally pervasive gender, the text of comics puts unique problems to the theory and practice of translation due to 
FAVERI, R.; SILVA-ReIS, D. - Comics in Translation

the two semiotic levels in its constitution. One example of this problem is the issue of adaptation that can be seen as intersemiotic translation (literary adaptation), editorial translation process (foreign $\mathrm{HQ}$ translated), or visual translation -the translation made by a translator/designer (roughly erasing a drawing and making another one over it).

After the symposium, some of the participants expressed their realization that even though we were facing, by one side, an ordinary translation process, at the same time we should acknowledge we do not have yet, a theoretical body and/or research in order to help and indicate solutions to problems that, in relation to comics, individual works present. But creativity had its way on the occasion of the symposium and the participants were creative enough both in their presentations and in the articles in this dossier, as it is possible to see in the texts that follow.

From the initiative of assembling the symposium, a small set of proposals about comics translation started to emerge. We are presently facing a considerable increasing on the amount of academic works on the subject, but they are scattered among academic journals and Brazilian libraries and/or databases. For this reason we felt moved towards the preparation of this dossier.

The so-called language of comics is not the same as that of narrative prose, it is possibly closer to the poetic narrative and the discourse of advertising. Reflecting upon the translation of comics cannot rely solely on tradition or traditions of translation. At the same time, the practice of comics translation is widespread and the public of comics in Brazil consumes and depends proportionally on a much larger percentage of the product of translations than on original works.

This dossier presents a series of articles submitted by symposium participants and other invited authors. Although there are many other possible approaches to the subject, we think that the articles here are just a tip of the iceberg of this field of Translation Studies starting to establish itself 
in Brazil. We are grateful to all the contributors in this publication by their patience, creativity and quality of research.

Special gratitude to John Milton for his intermediation between the dossier's editors and the TradTerm journal, and also to the editorial board of the journal, through Prof. Lineide Mosca, for their patience, timing, cooperation and acceptance of the papers published here.

Finally, it is our wish readers will enjoy the articles and topics presented and discussed ahead. We also hope they find them instructive to the problems posed by the inquiry on comics translation both to translators and readers in Brazil today. 